\title{
A Constituição da Problemática da Violência contra Homossexuais: a Articulação entre Ativismo e Academia na Elaboração de Políticas Públicas
}

\author{
SILVIA RAMOS \\ SÉRGIO CARRARA
}

A violência contra homossexuais tem representado um tema central para o ativismo, para governos e para a mídia. O objetivo deste artigo é analisar os principais aspectos das agendas do movimento homossexual, isto é, de seus discursos e práticas voltadas para influir nas políticas públicas para enfrentar a violência. Em especial, interessa-nos identificar as relações entre ativismo e academia nesses processos e o modo pelo qual, a partir dessa relação, um certo tipo de conhecimento vem sendo produzido no Brasil.

Palavras-chave: Violência; homossexualidade; políticas públicas.

Recebido em: 29/06/2006.

Aprovado em: 05/09/2006. 
Desde os anos 1980, a violência contra homossexuais tem representado um tema central para o ativismo e, progressivamente, também para governos e para a mídia. A denúncia de agressões e discriminações motivadas pela orientação sexual ou sexualidade passou a ser marco importante para a trajetória do movimento homossexual brasileiro, que divulgou a expressão "homofobia" para caracterizar esse tipo de violência.

De fato, o tema da violência foi estruturante para a constituição de outras matrizes de identidades coletivas no Brasil, como ocorreu com o movimento de mulheres no final dos anos 1970, que elegeu "quem ama não mata" como uma de suas bandeiras e definiu a criação das Delegacias Especializadas de Atendimento à Mulher como uma de suas primeiras demandas. ${ }^{1}$ Processo semelhante ocorreu com o movimento negro, que estabeleceu o racismo e sua criminalização ${ }^{2}$ como a principal trincheira de luta nos anos 1980 e 90 . Nos três casos, as "violências específicas" - violência de gênero, racismo e homofobia aparecem como âncoras a partir das quais outras reivindicações se estruturam e, sobretudo, se legitimam.

O objetivo deste artigo é analisar os principais aspectos das agendas do movimento homossexual, isto é, de seus discursos e práticas voltadas para influir nas políticas públicas para enfrentar a violência. Em especial, interessa-nos identificar as relações entre ativismo e academia nesses processos e o modo pelo qual, a partir dessa relação, um certo tipo de conhecimento vem sendo produzido no Brasil. Analisaremos a produção de dossiês sobre assassinatos de homossexuais pelo Grupo Gay da Bahia, a partir da década de 1980, a criação do banco de dados do Disque Defesa Homossexual em 1999, no Rio de Janeiro, a investigação sobre processos penais sobre assassinatos de homossexuais, também no Rio de Janeiro e, finalmente, os surveys de vitimização realizados nas paradas do orgulho GLBT, em 2003, 2004 e 2005.

\section{A cena homossexual na segunda metade dos anos 1990 e as novas características do ativismo}

Em junho de 2006, a Parada do Orgulho GLBT ${ }^{3}$ de São Paulo reuniu, segundo estimativa dos organizadores, mais de dois milhões de participantes e teve como lema central "Homofobia é crime: direitos sexuais são direitos humanos". O vigor desse tipo de manifestação de massa (em 2006, paradas do orgulho ocorreram em 77 cidades brasileiras) ${ }^{4}$ guarda estreita relação com 
as novas configurações que o movimento homossexual adquiriu na segunda metade dos anos 1990.

Facchini (2005) propõe uma periodização do movimento homossexual, considerando uma "primeira onda", demarcada pelo surgimento do Grupo Somos e do jornal O Lampião da Esquina (1978), e uma "segunda onda", associada ao surgimento dos grupos Triângulo Rosa (Rio de Janeiro), Grupo Gay da Bahia (Salvador) e também do Atobá (Rio de Janeiro), nos anos 80. Identifica uma "crise" nos primeiros anos da epidemia de Aids e um "reflorescimento" do ativismo nos anos 1990 (FACCHINI, 2005, p. 87-184). Uma das características desse novo período são a diversificação e especificação crescentes das categorias identitárias abarcadas pelo movimento, em um modelo que, inspirado na experiência internacional, especialmente na norte-americana, é definido por Facchini como "segregacionista". Efetivamente, os nomes de encontros nacionais de entidades homossexuais ao longo dos anos 80 e 90 expressam a diversidade de siglas, multiplicadas para acomodar as diferentes expressões identitárias produzidas através de um processo contínuo de segmentação.

Assim, se os seis primeiros encontros (1980-1992) foram chamados de Encontros Brasileiros de Homossexuais, o sétimo (1993) passou a se chamar de Encontro Brasileiro de Lésbicas e Homossexuais; o oitavo, de Encontro Brasileiro de Gays e Lésbicas; o nono (1997) intitulou-se Encontro Brasileiro de Gays, Lésbicas e Travestis. Depois disso, até o XII Encontro, realizado nas dependências do Congresso Nacional, em 2005, os encontros foram designados como Encontros Brasileiros de Gays, Lésbicas e Transgêneros.

Utilizada para designar simultaneamente travestis e transexuais, a categoria transgênero é atualmente foco de grande polêmica, encontrando grande resistência entre as travestis (FACCHINI, 2005). Talvez por essa razão, no XII Encontro Nacional decidiu-se que o movimento, além de incluir bissexuais, passaria a designar pelo " $\mathrm{T}$ " de sua sigla travestis e transexuais $\mathrm{e}$ não mais transgêneros. Desse modo, o que chamamos de movimento homossexual, ou o antigo Movimento Homossexual Brasileiro, é agora Movimento de Gays, Lésbicas, Bissexuais, Travestis e Transexuais ${ }^{5}$ (VIANNA; CARRARA, no prelo).

Outra característica marcante do movimento é sua crescente organização por meio de grupos que se inspiram no modelo de "ONGs" (organizações não-governamentais). Até 1990, os encontros brasileiros reuniam de seis a oito grupos. Em 1995, a ABGLT (Associação Brasileira de Gays, 
Lésbicas, Bissexuais e Transgêneros) foi fundada por 31 grupos. Em 2006, o site da ABGLT registrava uma rede nacional de 165 organizações, sendo 109 grupos de gays, lésbicas, travestis e transexuais, e mais 56 organizações colaboradoras voltadas para os direitos humanos e a Aids. De fato, a "onguização" de movimentos sociais é uma característica não só do movimento homossexual, sendo também muito acentuada no movimento feminista na América Latina (ALVAREZ, 2000). Entre outros aspectos, o que caracteriza esse processo é a valorização da competência técnica (em oposição à idéia de "representatividade"); a profissionalização e a especialização da militância; a tendência à diversificação e à multiplicação; o diálogo com experiências internacionais; a busca de autonomia em relação ao Estado, combinada com a disputa por recursos para a manutenção de estruturas que tendem a incluir sedes, equipamentos e funcionários (FERNANDES, 1988; ALVAREZ, 2000; FACCHINI, 2005).

Além da multiplicação de organizações e da criação de entidades nacionais, ${ }^{6}$ na segunda metade dos anos 1990, uma série de processos e acontecimentos, heterogêneos e pouco articulados entre si, seria responsável por mudanças consideráveis no quadro de refluxo que caracterizou o movimento na década de 1980 e nas próprias representações sociais sobre a homossexualidade, tradicionalmente marcadas pelo estigma e pelo desvio.

O primeiro desses processos ocorre no âmbito do Legislativo e do Judiciário, onde emergem diferentes iniciativas visando à coibição da discriminação e à ampliação de direitos. Formulada no período de refluxo do movimento, a Constituição de 1988 não incluiu a expressão "orientação sexual" no artigo que proíbe discriminação por "origem, raça, sexo, cor e idade" e no artigo que versa sobre os direitos do trabalho. Mesmo assim, além dos projetos de emenda constitucional que tramitam no Congresso, mais de 70 municípios contam atualmente com alguma legislação que prevê proteção contra a discriminação, e oito estados, além do Distrito Federal, sancionaram medidas importantes para coibi-la (VIANNA; LACERDA, 2004). Também tramita um importante projeto para alterar o Código Penal e a Lei $n^{\circ} 7.716$, que criminaliza o preconceito de cor ou raça, para incluir punição também à discriminação e preconceito de gênero e orientação sexual. Finalmente, a expressão mais emblemática do processo de ampliação de direitos via Poder Legislativo é o projeto de lei apresentado à Câmara Federal em 1995, objetivando regular a "união civil entre pessoas do mesmo sexo". 
Aprovado por uma Comissão especial em 1996, o projeto foi modificado em diversos pontos, inclusive na substituição do termo "união" por "parceria". A despeito de suas limitações, o projeto deu enorme visibilidade às discussões em torno dos direitos de gays, lésbicas e transgêneros na mídia nacional. Embora haja vozes dissonantes, o mainstream do movimento, liderado pela ABGLT, apóia o projeto, que, para alguns, representa um passo em direção a uma lei mais abrangente. ${ }^{7}$ Além dos diferentes corpos legislativos, o Judiciário tem-se mostrado outra arena fundamental para a construção de novos direitos. Em muitos casos, especialmente nos que envolvem direitos previdenciários, ações judiciais - e suas respectivas sentenças - abriram caminho para mudanças legislativas, de tal forma que próximo do fim dos anos 90 houve, por exemplo, uma veloz multiplicação do número de sistemas de previdência de governos estaduais e municipais que passaram a estender a parceiros homossexuais direitos previstos aos cônjuges.

O segundo processo de transformação importante para a cena homossexual nos anos 1990 é a consolidação de um relativamente vigoroso mercado de bens e serviços destinados a homens e mulheres homossexuais. Constituído inicialmente por bares, boates e saunas, esse circuito comercial passa a também agregar sites, festivais de cinema, revistas especializadas, editoras, hotéis, empresas de turismo, grifes de moda etc. De forma não homogênea e apresentando características próprias de região para região, a proliferação dessas experiências comerciais contribuiu, em alguns locais, para o aparecimento de uma combinação entre militância e mercado, rara na tradição da esquerda brasileira. Juntas, essas iniciativas passaram a constituir novos espaços de sociabilidade, inscrevendo-se, com alguma freqüência, nos marcos de um compromisso com a formação de uma "identidade positiva" e a melhoria da "auto-estima". A despeito dos diversos problemas resultantes da forte segmentação desse mercado e a conseqüente exclusão de certos grupos (por exemplo, a proibição de freqüência de travestis em estabelecimentos gays), em algumas cidades o chamado "mercado GLS" o ativismo homossexual, como é o caso de São Paulo (FRANÇA, 2006).

Articulado às iniciativas anteriores, o terceiro processo de transformação que ocorre nos anos 1990 diz respeito à adoção, por ativistas e por homossexuais não-organizados, da política de visibilidade maciça e o surgimento das paradas do orgulho. Aparecendo no meio da década passada, as paradas passaram a integrar esforços tanto da militância organizada em ONGs, como de ativistas 
independentes. Atualmente, as paradas reúnem milhares de pessoas em dezenas de cidades brasileiras. Muitas contam com apoio financeiro do Ministério da Saúde, algumas com apoio do Ministério da Cultura e diversas com apoios de prefeituras e secretarias estaduais. Nas paradas mais importantes, ocorrem parcerias com empreendimentos privados, sobretudo bares e boates gays e lésbicos, que instalam nas paradas seus carros de som.

Finalmente, o quarto e último processo a ser aqui destacado relacionase à multiplicação de iniciativas no ambiente acadêmico e universitário, com a incorporação dos temas relacionados à homossexualidade e ao "homoerotismo" nas pautas das pesquisas das Ciências Humanas e Sociais em centros de estudos e universidades do país. Em 2001 foi criada, em encontro realizado na Universidade Federal Fluminense, a Associação Brasileira de Estudos da Homocultura (ABEH), que realiza congressos bianuais em universidades brasileiras. Uma busca na Plataforma Lattes, do CNPq, com as palavras "homoerotismo", "homossexualidade", "gay", "lésbica" e "queer", resultou em nada menos do que 1.420 pesquisadores trabalhando com esses temas em junho de 2006. ${ }^{9}$ Nesse aspecto, o quadro instaurado na segunda metade dos anos 90 já era bastante diverso daquele dos anos 80 , quando poucos intelectuais, geralmente mantendo também atividades de militância, dedicavam-se ao estudo dos temas relativos à homossexualidade no Brasil.

É no âmbito desse curto mas intenso processo de transformação social envolvendo os poderes públicos, o ativismo GLBT, o mercado e a academia, que os estudos sobre a violência contra homossexuais ou violência homofóbica no Brasil devem ser compreendidos.

\section{Representações da violência: assassinatos de homossexuais e os dossiês do Grupo Gay da Bahia}

Criado em 1980, o Grupo Gay da Bahia (GGB) antecipou o modelo que seria adotado pela maioria das organizações homossexuais na década seguinte. Juntamente com o grupo Triângulo Rosa, do Rio de Janeiro, o GGB buscava uma militância mais pragmática, voltada para a conquista de direitos e a denúncia de violências, já preocupada com o grau de institucionalidade dos grupos (CÂMARA, 2002; FACCHINI, 2005). No caso do GGB, isto significou a providência de registro legal e a busca do reconhecimento como instituição de utilidade pública. 
Segundo seu fundador, o antropólogo e ativista Luiz Mott, desde 1980 o GGB passou a arquivar informações sobre violência contra homossexuais, tendo reunido o registro documentado de assassinatos "onde explícita ou indiretamente, o motivo da morte foi a condição homossexual da vítima"10 (MOTT, 2002). Esses registros, formados na sua grande maioria por notícias publicadas em jornais, e secundariamente por comunicação de militantes,${ }^{11}$ foram divulgados por meio de dossiês que se tornaram célebres e permitiram conhecer e denunciar crimes violentos contra homossexuais, sobretudo a partir dos anos 1990. Em grande medida, as denúncias sistemáticas de assassinatos de homossexuais estimuladas pelo GGB ajudaram a romper o silêncio sobre o assunto.

Em 1988, quando do assassinato do diretor teatral Luiz Antônio Martinez Correa, no Rio de Janeiro, os grandes jornais passaram a utilizar a expressão "assassinatos de homossexuais" para problematizar e reconhecer a existência de um "tipo de crime" que até então tendia a ser noticiado como episódios isolados (LACERDA, 2006). Na ocasião, começam também a aparecer nas páginas dos jornais vozes de ativistas de grupos homossexuais, como autores de interpretações sobre a "natureza específica" dessa violência. Ao mesmo tempo, artistas e "personalidades" identificadas como porta-vozes dos homossexuais aparecem denunciando que "o preconceito contra homossexuais" explicaria o pouco interesse na investigação dos casos pela polícia. Lacerda (2006), em seu estudo baseado em jornais cariocas de 1980 a 2000, observa que em 1992 aparece pela primeira vez a expressão "homofobia", no jornal $O$ Globo, para designar "horror ao homossexual" (LACERDA, 2006, p. 107). Na segunda metade dos anos 90, a divulgação de "estatísticas", pelo GGB e pelo Grupo Atobá (fundado em 1985, no Rio de Janeiro), torna-se freqüente e vem acompanhando sistematicamente a divulgação de novos casos de assassinatos.

A preocupação com a elaboração de um arquivo e a divulgação de relatórios ${ }^{12}$ contabilizando casos de assassinatos de homossexuais contribuiu fortemente para estabelecer uma das prioridades da agenda do movimento, a denúncia da "violência contra homossexuais" e da "homofobia". Contudo, a abordagem predominantemente sensacionalista da imprensa, sobretudo durante a década de 1980 e em parte da década de 1990, favoreceu uma visão parcial da vitimização de homossexuais que muitas vezes tendia a "confirmar" - até mesmo para o próprio movimento - representações vigentes sobre a homossexualidade, nas quais a tragédia era, de alguma forma, efeito de fraquezas 
morais e de escolhas das próprias vítimas. Essas representações eram particularmente fortes no caso de as vítimas serem travestis e no caso de assassinatos de homossexuais de classe média por garotos de programa.

A ênfase na violência letal, a exposição de cadáveres e a reiteração da tragédia consumada podem ter contribuído para afastar, até o final dos anos 1990, o ativismo homossexual de uma postura mais propositiva sobre a temática da violência. ${ }^{13}$ Diferentemente do movimento de mulheres - que nos final dos 70 e na década de 80 elaborou uma agenda com a demanda pela criação de delegacias policiais especializadas, entre outras reivindicações -, o movimento homossexual permaneceu até fins dos anos 90 na perspectiva da denúncia, afirmando uma representação dos homossexuais como "vítimas" de uma violência que não podiam evitar. ${ }^{14}$ Também é notável o contraste entre a postura predominantemente passiva no campo de propostas para a segurança pública e justiça e o vigor dos discursos, demandas e práticas que o ativismo homossexual produziu na área da saúde. A criatividade, a irreverência ("transe numa boa"15), as reivindicações e principalmente a focalização em certos aspectos do combate à epidemia de Aids (por exemplo, acesso público, gratuito e universal a medicamentos), além da participação direta de ativistas em ações de prevenção, foram responsáveis em grande medida pelos rumos das respostas brasileiras à epidemia de Aids (GALVÃO, 2000).

\section{O Disque Defesa Homossexual e novas relações entre ativismo e academia na formulação de políticas públicas}

É no panorama do final dos anos 90, já no contexto de multiplicação de ONGs e redes, na presença das paradas do orgulho, da internet e de um mercado que crescia, que acontece a primeira experiência de política pública na esfera da segurança, o Disque Defesa Homossexual (DDH). Criado em 1999, na Secretaria de Segurança do Rio de Janeiro, o DDH foi pensado como um programa de defesa (e não apenas de denúncia). O projeto configurou uma experiência de estabelecimento de parcerias diretas entre polícia e grupos de ativistas, no sentido de fazer agir com rapidez tanto dispositivos de prevenção de crimes (acionando a força policial em locais e situações de incidência de violência), como de atendimento às vítimas dos crimes já ocorridos (mobilizando a polícia para investigar agressores e golpistas e articulando redes de apoio psicológico e jurídico por parte das ONGs). 
A experiência foi desenvolvida no contexto de um conjunto de programas na área de segurança pública que preconizava a democratização e modernização do aparelho policial, prevendo intensa participação de organizações da sociedade civil. ${ }^{16} \mathrm{~A}$ criação do DDH foi baseada em articulações que envolveram diversos atores: a secretaria de Segurança, todas as entidades do movimento homossexual do Rio de Janeiro, o ISER (Instituto de Estudos da Religião), uma ONG voltada para a pesquisa, um mandato parlamentar (de Carlos Minc, deputado estadual pelo PT) e dois pesquisadores do Instituto de Medicina Social da Universidade do Estado do Rio de Janeiro (MARTINS, 2001). Os acontecimentos deflagradores das demandas do movimento homossexual à secretaria de Segurança, que posteriormente motivaram a idealização do DDH, foram sucessivas agressões sofridas por jovens gays numa área de bares e boates GLS em Botafogo, bairro da Zona Sul do Rio de Janeiro, e o despreparo da polícia para atender a essas ocorrências.

Um dos diferenciais da criação do DDH em relação a experiências anteriores de denúncia à violência contra homossexuais foi a presença, como atores políticos da articulação, de pesquisadores ligados a uma ONG e a uma universidade. $\mathrm{O}$ fato foi decisivo para que o programa fosse concebido não só como um serviço de atendimento a vítimas, mas também como um centro de produção de dados sobre violência. ${ }^{17}$ Uma outra diferença da experiência é que, até então, os conhecimentos sobre vitimização de homossexuais e a caracterização da violência homofóbica no Brasil eram baseados em notícias publicadas em jornais. Os dados gerados pelo DDH partiam dos relatos das próprias vítimas e, portanto, passaram a problematizar variadas situações de agressão e discriminação associadas à homofobia e não só os assassinatos. ${ }^{18}$

A análise dos primeiros 500 casos atendidos pelo programa revelou a intensidade de dinâmicas cotidianas e silenciosas de homofobia. A maioria das denúncias era constituída de casos de ofensas, ameaças, extorsões, agressões físicas e uma grande quantidade de queixas de "discriminações" (na escola, no trabalho, no comércio e também na família e na vizinhança), além dos conflitos de natureza interativa entre parceiros. Nada menos de que um terço dos casos relatados ao DDH se dava no âmbito da casa ou da vizinhança, indicando a intensidade de crimes não-espetaculares e não-letais, gerados e vividos em escala micro-societária, na esfera da família e de conhecidos. Uma criminalidade, em geral, sem fins lucrativos, em que vítimas e agressores partilham as mesmas redes sociais (RAMOS, 2001). 
O estudo propôs uma matriz de análise dos casos, classificando-os como: 1) crimes interativos (agressões e discriminações ocorridas no âmbito da casa, da vizinhança e entre parceiros, das quais as lésbicas - e não só gays e travestis - apareciam como vítimas em proporções expressivas); 2) crimes com fins de lucro (chantagens, extorsões, assaltos e golpes do tipo "Boa Noite Cinderela", 19 em geral praticadas contra gays e travestis); 3) crimes de ódio (espancamentos, graves ameaças à vida e denúncias de assassinatos), na maioria dos casos contra travestis.

A experiência do DDH inspirou diversas outras iniciativas apoiadas por governos de estados e prefeituras do país. No Rio de Janeiro, o programa foi parcialmente descontinuado após março de 2000 , quando a equipe que coordenava os Centros de Referência deixou a secretaria de Segurança (MARTINS, 2001), interrompendo-se a sistemática de coleta e análise dos dados.

\section{Assassinatos de homossexuais no Rio de Janeiro: uma pesquisa sobre a Justiça}

Partindo de 200 notícias levantadas a partir do dossiê de recortes de jornal mantido pelo grupo 28 de Junho, do Rio de Janeiro, Carrara e Vianna (2001) localizaram 105 registros de ocorrência policial sobre homicídios de homossexuais, que resultaram em 80 processos na Justiça. Desses, analisaram 57. Os resultados da investigação foram muito importantes porque - embora não conclusivos nem estatisticamente representativos - pela primeira vez foi possível examinar a hipótese de que predomina a lógica da "impunidade" no sistema de justiça criminal quando as vítimas são homossexuais. Uma das surpresas foi a constatação de que os crimes letais resultantes de "latrocínio" (em geral gays de classe média vítimas de garotos de programa dentro de suas residências) constituíam um universo especial, devido a caracterizações estigmatizantes da vítima por agentes da polícia e da justiça, por um lado, e pela taxa surpreendentemente alta de condenações nos casos em que os réus tinham sido indiciados.

A pesquisa concluiu que a homofobia se articula de forma mais complexa e sutil e afeta as representações relativas à homossexualidade mantidas por policiais, promotores, juízes e advogados, sem se materializar necessariamente em absolvições ou sentenças tolerantes, mas sim no uso de clichês sobre a homossexualidade e as dinâmicas das relações no mundo homossexual. Além de reiterarem a idéia de que as vítimas contribuíram para sua morte, com uma 
"vida de risco" ou como reféns de uma "patologia", tais representações determinam os rumos das investigações e etapas dos processos, mesmo nos casos em que há condenação (CARRARA; VIANNA, 2001). O trabalho também concluiu que a violência que atinge homossexuais é mais heterogênea e complexa do que o modelo clássico do crime de ódio, marcando certa diferença em relação a abordagens anteriores, mais diretamente vinculadas ao ativismo e a suas estratégias.

\section{As pesquisas nas paradas do orgulho GLBT a partir de 2003}

Em 2003, centros de pesquisa e instituições universitárias ${ }^{20}$ iniciaram um ciclo de pesquisas nas paradas do orgulho GLBT em algumas cidades brasileiras. Abordando questões variáves sobre sociabilidade, afetividade, sexualidade, política e direitos, e questões fixas sobre violência e discriminação, a principal característica do projeto é a articulação entre centros de pesquisa e grupos de ativistas. ${ }^{21}$

O projeto parte do reconhecimento de que as paradas são, além de fenômeno social e político dos mais expressivos no Brasil urbano, eventos que reúnem gays, lésbicas, travestis, transexuais e bissexuais que, de outro modo, dificilmente poderiam ser alcançados por uma investigação sociológica, oferecendo oportunidade ímpar para que sejam mais bem conhecidos. Dadas, sobretudo, as segmentações geracionais, de classe e identitárias que marcam essa população, esta não poderia ser abordada em sua extrema diversidade em qualquer outro espaço social (seja de lazer, trabalho ou mesmo de ativismo político). Além disso, as paradas se organizam justamente em torno de uma espécie de denominador comum que agrega todo esse universo, a luta contra a discriminação e o preconceito que atingem diferentes "minorias sexuais". Nesse sentido, a pesquisa nas paradas se inscreve dentro dos marcos da pesquisa aplicada e representa uma nova experiência de articulação entre ativismo e academia. ${ }^{22}$

Em relação aos temas da violência, o projeto utiliza uma estratégia denominada "pesquisa de vitimização", isto é, a mensuração da incidência de agressões e discriminações em toda a população entrevistada. Partindo das indicações obtidas nos registros ao DDH e do surgimento de demandas a cada rodada de entrevistas, a pesquisa na parada passou a trabalhar com uma categorização de homofobia que divide as experiências de violência em duas grandes categorias: as "discriminações" e as "agressões". Entre as 
discriminações são mensuradas as experiências de "marginalização, exclusão ou mal atendimento" nas situações de trabalho; comércio ou lazer; escola ou faculdade; serviços de saúde; doação de sangue; delegacias de polícia; contexto religioso; contexto familiar; relações com amigos ou vizinhos. Entre as agressões são mensuradas experiências que poderiam ser mais facilmente criminalizadas, nos termos do Código Penal vigente: agressões físicas; agressões verbais ou ameaça de agressão física; violência sexual; chantagens, extorsões e golpes como o "Boa Noite Cinderela".

Os resultados caracterizam a homofobia como sendo altamente variável segundo marcadores de gênero, identidade sexual e idade (e secundariamente por escolaridade e cor). As pesquisas vêm confirmando impressões iniciais obtidas na experiência do DDH, de que violência e homossexualidade mantêm relações mais complexas e contraditórias do que as imagens veiculadas pela mídia e pelo ativismo dos anos 80 faziam supor (CARRARA, RAMOS, CAETANO, 2004; CARRARA, RAMOS, 2005; CARRARA et al., 2006).

Os resultados gerais apontam que a incidência de discriminação e de agressão é muito consistente nos surveys do Rio, Porto Alegre e São Paulo. Surpreende que algumas experiências homofóbicas, como por exemplo, sofrer agressão verbal, são relatadas por mais de $60 \%$ de entrevistados, independentemente de gênero, idade, cor ou orientação homossexual. Outro resultado que chama a atenção e que se coloca em contraste marcante com o "panorama da visibilidade maciça" é a proporção muitíssimo reduzida de denúncias comunicadas aos órgãos públicos (uma parcela próxima a 10\% relata ter feito registros na polícia. Denúncias à imprensa e a ONGs ocorrem em proporções ainda menores, abaixo de 5\%).

Está claro o descompasso entre a alta incidência de vivências homofóbicas por parte expressiva da população entrevistada (o que produz indicativos consistentes acerca da alta incidência no conjunto da comunidade GLBT, considerados os resultados reiterados nas diversas rodadas) e as ainda tímidas demandas por políticas de segurança e justiça voltadas para coibi-las.

\section{Brasil sem homofobia}

Segundo Vianna e Lacerda (2004), “o reconhecimento da especificidade e, ao mesmo tempo, da diversidade de formas de violência que atingem homossexuais" fundamenta a criação, pelo Governo Federal, do "Brasil Sem 
Homofobia: Programa de Combate à Violência e à Discriminação contra GLBT e de Promoção da Cidadania Homossexual", lançado em maio de 2004. ${ }^{23}$ Segundo as autoras, "o programa foi elaborado por uma comissão do Conselho Nacional de Combate à Discriminação e pelo Ministério da Saúde, com a participação de vários ativistas e organizações militantes", como a ABGLT. Em seus dez itens, o programa prevê um conjunto bastante amplo de ações, com destaque para a política para mulheres lésbicas e a articulação do combate ao racismo e à homofobia. Entre as ações, destacam-se: (i) as que visam a capacitar o Estado, especialmente instituições escolares, policiais, judiciais, de saúde e de fiscalização do trabalho, a atuar de modo não-discriminatório, seja através da mudança de suas práticas, seja através da criação de novos dispositivos, como DDHs e centros de referência nas secretarias estaduais de Segurança Pública, especialmente desenhados para coibir a violência e a discriminação; (ii) o incentivo à participação de lideranças do movimento nos diferentes conselhos e mecanismos de controle social do Governo Federal; (iii) a produção de conhecimento sobre violência e discriminação homofóbicas e sobre as condições de saúde de gays, lésbicas e transgêneros; e finalmente, (iv) o apoio às iniciativas brasileiras no plano internacional, no sentido do reconhecimento e proteção dos direitos GLBTs e à criação de uma Convenção Interamericana de Direitos Sexuais e Reprodutivos.

Algumas das diretrizes do programa têm sido executadas, estreitando ainda mais a articulação entre Estado e sociedade civil. Em meados de 2005, a Secretaria Geral da Presidência da República lançou edital aberto a instituições públicas ou não-governamentais para seleção de projetos de prevenção e combate à homofobia, através da prestação de assessoria jurídica e psicossocial às vítimas, da orientação e encaminhamento de denúncias, da capacitação em direitos humanos e da mediação e conciliação de conflitos. No final de 2005, uma das instituições selecionadas nesse concurso - o Estruturação, Grupo de Lésbicas, Gays, Bissexuais e Transgêneros de Brasília - assinou convênio com a Secretaria Especial de Direitos Humanos do Governo Federal, para criação de um Centro de Referência LGBT, para prestação de serviços às vítimas de discriminação. Também em 2005, o Ministério da Educação lançou edital público para seleção de projetos de capacitação de profissionais de educação em temas relativos à orientação sexual e identidade de gênero. Dos 84 projetos apresentados no prazo, 36 eram liderados por organizações não-governamentais, sobretudo grupos GLBT, 24 por órgãos governamentais (prefeituras, secretarias municipais e estaduais de Educação) e seis por universidades. Desses projetos, 48 foram 
recomendados e 15 selecionados. Entre os selecionados, 12 foram propostos por organizações não-governamentais, dos quais sete de grupos GLBT, dois por universidades e apenas um por um órgão governamental (secretaria municipal de Educação). Como se vê, a tendência do ministério é apoiar principalmente projetos propostos por grupos militantes e organizações não-governamentais.

\section{Homofobia e políticas públicas: perspectivas para a década atual}

O movimento homossexual tem pela frente um dilema político que exigirá cuidados. Se, por um lado, a representação coletiva dos homossexuais como "vítimas" da homofobia encontra suporte nas pesquisas sobre violência, também é fato que as experiências são fortemente matizadas por sexo, identidade sexual, idade, classe e cor. Para a maior parte das discriminações e agressões, travestis e transexuais encontram-se num extremo da escala de vitimização, e bissexuais, lésbicas e gays jovens, noutro. Além disso, um contingente estatisticamente importante da comunidade não refere qualquer experiência de vitimização (entre $30 \%$ a $40 \%$ dos entrevistados nas diversas paradas).

Comparativamente a outros movimentos de identidade (movimento de mulheres e movimento negro), o movimento homossexual foi historicamente lento na elaboração de demandas de políticas públicas integradas para responder aos fenômenos da homofobia. Fixou-se durante muito tempo num modelo estereotipado de "violência contra homossexuais" (os assassinatos) que, ao final, correspondia apenas a uma parte das diversas dinâmicas cotidianas de violência sofridas por gays, lésbicas, bissexuais e transgêneros. Nesse sentido, o discurso do ativismo sobre "homofobia" produzia impacto reduzido não só junto à comunidade homossexual, mas também junto aos governos e à mídia.

As experiências do tipo do DDH e as pesquisas desenvolvidas a partir da década atual passaram a demonstrar que, em contraste com as dinâmicas de violências de gênero e de racismo (que por serem mais homogêneas permitem respostas focalizadas), a homofobia opera com muitas variáveis e engloba fenômenos díspares, que vão desde discriminações na esfera doméstica a crimes com fins de lucro. Por essa razão, as estratégias de enfrentamento desses fenômenos e os discursos produzidos pelo movimento homossexual têm que reconhecer essa complexidade e mobilizar demandas específicas para diferentes violências. Por exemplo, a experiência do DDH demonstrou que, para responder às chantagens, extorsões, golpes tipo "Boa Noite Cinderela" e latrocínios 
motivados pela sexualidade, é necessário haver: a) incremento sistemático das denúncias à polícia; b) investigação policial, prisão de criminosos e de quadrilhas de golpistas, inclusive as formadas por policiais e ex-policiais; c) divulgação de "casos exemplares" bem-sucedidos na imprensa; d) campanhas de esclarecimento lideradas pelo próprio movimento GLBT voltadas para a comunidade; e) monitoramento dos resultados junto às secretarias de Segurança.

Por outro lado, as respostas para as dinâmicas de discriminação na esfera da família e círculos de amizade demandam não só campanhas específicas de informação e mobilização, mas atendimento individual às vítimas, por meio de uma rede de apoio e proteção, nos moldes da experiência do movimento de mulheres em relação à violência de gênero. Os altos índices de homofobia registrados nas escolas, por exemplo, indicam a necessidade de mais pesquisas e da criação de programas especiais envolvendo autoridades educacionais, professores e alunos. As violências conjugais, especialmente graves e invisíveis entre lésbicas, são temas que o movimento GLBT tem que enfrentar, levando em conta as especificidades das diversas identidades sexuais.

Outro desafio são as representações "concorrentes" com a idéia de que a homofobia é constitutiva da experiência homossexual. As imagens ligadas ao orgulho e à afirmação - e, no extremo, à beleza, à alegria e ao consumo - são capitaneadas pela mídia e pelas iniciativas de mercado, e disputam a hegemonia das representações da homossexualidade, sendo possível observar grande tensão quanto às representações ativistas, ainda que até agora se observe uma convivência relativamente pacífica durante as celebrações das paradas do orgulho (RAMOS, 2005).

Tudo indica que será necessário, nos próximos anos, um esforço ainda maior de incorporação de organizações de travestis e transexuais dentro do movimento GLBT, na medida em que são esses grupos que vivem as experiências mais críticas de violência e que, portanto, devem exercer papel decisivo na elaboração de demandas de políticas e na participação direta em práticas de prevenção, como ocorreu no processo de respostas à epidemia de Aids.

Por último, um dos dilemas atuais pode ser resumido em: exigir respeito, mas não perder a irreverência GLBT e a afirmação da sexualidade; demandar a criminalização da homofobia, mas não a regulação da diversidade sexual. Experiências de segurança pública, em que a afirmação da sexualidade foi combinada com a demanda por segurança e respeito das autoridades policiais 
(por exemplo, direito à "pegação" em ambiente seguro e livre de extorsão) podem ser indicadores de que é possível "ser vítima" e "ter orgulho", numa relação criativa e pró-ativa com as políticas de segurança pública.

\section{Referências}

ALVAREZ, Sonia. A "globalização" dos feminismos latino-americanos. In: ALVAREZ; DAGNINO; ESCOBAR (Orgs.). Cultura e política nos movimentos sociais latino-americanos. Belo Horizonte: Editora UFMG, 2000. p. 382-426.

CÂMARA, Cristina. Cidadania e orientação sexual: a trajetória do Grupo Triângulo Rosa. Rio de Janeiro: Academia Avançada. 2002. 182 p.

CARRARA, Sérgio; RAMOS, Silvia. Política, direitos, violência e homossexualidade: Pesquisa $9^{\mathrm{a}}$ Parada do Orgulho GLBT - Rio 2004. Rio de Janeiro: CEPESC, 2005. 115 p.

CARRARA, Sérgio; VIANNA, Adriana R. B. Homossexualidade, violência e justiça: a violência letal contra homossexuais no município do Rio de Janeiro. Relatório de pesquisa. IMS/UERJ/Fundação Ford, 2001. 90 p.

CARRARA, Sérgio et al. Política, direitos, violência e homossexualidade: Pesquisa $9^{\text {a }}$ Parada do Orgulho GLBT - São Paulo - 2005. Rio de Janeiro: CEPESC, 2006. 79 p.

CARRARA, Sérgio, RAMOS, Silvia; CAETANO, Marcio (Coords.). Política, direitos, violência e homossexualidade: $8^{a}$ Parada do Orgulho GLBT - Rio 2003. Rio de Janeiro: Pallas, 2003. 118 p.

CONSELHO NACIONAL DE COMBATE À DISCRIMINAÇÃO. Brasil sem homofobia: Programa de Combate à Violência e à Discriminação contra GLBT e de Promoção à Cidadania Homossexual. Brasília: Ministério da Saúde, 2004.

FACCHINI, Regina. Sopa de letrinhas? Movimento homossexual e produção de identidades coletivas nos anos 90. Rio de Janeiro: Garamond, 2005. 301 p.

FERNANDES, Rubem Cesar. Sem fins lucrativos. In: LANDIM, L. (Org.). Sem fins lucrativos: as organizações não-governamentais no Brasil. Rio de Janeiro: ISER, 1988. p. 8-23. 
FRANÇA, Isadora Lins. Cercas e pontes: o movimento GLBT e o mercado GLS na cidade de São Paulo. 2006. 262 p. Dissertação (Mestrado em Antropologia) - Faculdade de Filosofia, Letras e Ciências Humanas, Universidade de São Paulo, São Paulo, 2006.

GALVÃO, Jane. AIDS no Brasil: a agenda de construção de uma epidemia. São Paulo: Editora 34, 2000.

LACERDA, Paula. $O$ drama encenado: assassinatos de gays e travestis na imprensa carioca. 2006. 127 p. Dissertação (Mestrado em Saúde Coletiva) Instituto de Medicina Social, Universidade do Estado do Rio de Janeiro, Rio de janeiro, 2006..

MARTINS, Humberto Vieira. O que se conta e como se conta: um pouco da história do DDH. Comunicações do ISER, Ano 20, n 56, p. 40-52, 2001.

MOTT, Luiz ; CERQUEIRA, Marcelo. Causa mortis: homofobi. Violação dos direitos humanos e assassinato de homossexuais no Brasil - 2000. Salvador: Editora Grupo Gay da Bahia, 2001. 166 p.

MOTT, Luiz et al. O crime anti-homossexual no Brasil. Salvador: Editora Grupo Gay da Bahia, 2002. 180 p.

MOTT, Luiz. Violação dos direitos humanos e assassinato de homossexuais no Brasil - 1999. Salvador: Editora Grupo Gay da Bahia, 2000. 118 p.

RAMOS, Silvia. Disque Defesa Homossexual: narrativas da violência na primeira pessoa. 53-66. Comunicações do ISER, Ano 20, n. 56, 2001.

RAMOS, Silvia. Violência e homossexualidade no Brasil: as políticas públicas e o movimento homossexual. In: GROSSI, M. P. et al. (Orgs.). Movimentos sociais, educação e sexualidades. Rio de Janeiro: Garamond. 2005. p. 31-44.

SCHUMAHER, Schuma; BRAZIL, Érico. Dicionário de mulheres do Brasil. Rio de Janeiro: Jorge Zahar, 2000. 565 p.

TELLES, Edward. Racismo à brasileira: uma nova perspectiva sociológica. Rio de Janeiro: Relume Dumará, 2003. 347 p.

VIANNA, Adriana R. B.; CARRARA, Sergio. Sexual Politics and Sexual Rights in Brazil: a Case Study. No prelo.

VIANNA, Adriana R. B.; LACERDA, Paula. Direitos e políticas sexuais no Brasil: o panorama atual. Rio de Janeiro: CLAM/IMS, 2004. 245 p. 


\section{NOTAS}

- Doutoranda em Saúde Pública na ENSP/Fiocruz; coordenadora do Centro de Estudos de Segurança e Cidadania da Universidade Candido Mendes. Endereço eletrônico: sramos@candidomendes.edu.br.

- Professor adjunto no Departamento de Políticas e Instituições de Saúde, Instituto de Medicina Social da UERJ; coordenador do Centro Latino-Americano de Sexualidade e Direitos Humanos (CLAM). Endereço eletrônico: carrara@ims.uerj.br.

${ }^{1}$ Para uma periodização do movimento de mulheres no Brasil, ver Schumaher e Brazil (2000).

${ }^{2}$ Essa estratégia levou ao desenvolvimento de programas de atendimento de casos de violência racial por meio dos programas do tipo Disque-racismo em várias cidades brasileiras. Para uma discussão das legislações anti-racismo no Brasil, ver Telles (2003).

${ }^{3}$ Gays, Lésbicas, Bissexuais, Travestis e Transexuais.

${ }^{4}$ Veja em www.abglt.org.br

${ }^{5}$ Além das grandes categorias presentes na sigla GLBT, há também subgrupos incentivados pela proliferação de fóruns e listas de discussões na internet, como é o caso dos "ursos", "judeus gays", "advogados gays", "barbies", "jovens homossexuais” e outros (FRANÇA, 2006).

${ }^{6}$ Facchini argumenta que, a despeito da existência de uma associação nacional, o movimento permanece como um conjunto de entidades separadas, com formatos diversificados, que continuam surgindo a partir de "rachas" de outros grupos já existentes ou a partir de "projetos" desenvolvidos inicialmente dentro das entidades existentes que depois se autonomizam (FACCHINI, 2005, p. 277).

${ }^{7}$ A defesa da união ou parceria civil entre pessoas do mesmo sexo tem sido tema recorrente das principais paradas brasileiras. Em 2004, em Curitiba, a palavra de ordem foi "Família, Orgulho e Respeito"; no Rio de Janeiro, “União Civil Já!”; em Blumenau, "Homossexualidade, um Assunto Familiar”; e finalmente, em São Paulo, “Temos Orgulho e Família”. Em 2005, a parada de São Paulo, a maior já realizada no país e uma das maiores do mundo, tinha como tema "Parceria Civil, Já. Direitos Iguais! Nem Mais Nem Menos” (VIANNA, CARRARA, no prelo).

${ }^{8}$ Gays, Lésbicas e Simpatizantes.

${ }^{9}$ A mesma busca realizada em junho de 2001, por ocasião da fundação da Associação Brasileira de Estudos da Homocultura (ABEH), tinha resultado em 212 pesquisadores. O extraordinário crescimento nesse período deve ser parcialmente atribuído ao aumento do número de currículos na Plataforma. 
A constituição da problemática da violência contra homossexuais

${ }^{10} \mathrm{O}$ relatório "Assassinatos de homossexuais no Brasil: 2005", publicado no site do GGB, somava 2.511 vítimas entre 1980 e 2005 (www.ggb.org.br).

${ }^{11}$ Em 2001, dos 132 assassinatos registrados pelo GGB, 76\% tinham tido como fonte os jornais; $15 \%$ a internet e $9 \%$ informações orais, televisão ou cartas enviadas à entidade (MOTT, 2002, p. 56).

${ }^{12}$ Entre eles: MOTT (1999); MOTT, CERQUEIRA (2001) e MOTT et al. (2002).

${ }^{13}$ Uma reação defensiva da militância pode ter sido ainda mais acentuada pelo fato de o ativismo se constituir sobretudo por segmentos médios e pelo fato de travestis e transexuais aparecerem tardiamente como atores políticos e sociais no movimento.

${ }^{14}$ Mott (2002, p. 65-66) responde à crítica de que "a divulgação de crimes contra homossexuais perpetuaria a postura de vitimismo", afirmando que "dentre todas as minorias sociais, os homossexuais constituem o segmento mais discriminado [...]. Ao denunciar e protestar contra o homicídio de homossexuais, jamais tratamos gays, lésbicas e transgêneros como 'coitadinhos' incapazes de enfrentar e superar tais violências. Pelo contrário, retratamos realisticamente a força da maldade da homofobia com vistas a sensibilizar não só os donos do poder e a sociedade global, mas sobretudo as próprias vítimas potenciais dessa guerra sangrenta, a fim de que, reagindo e evitando situações risco, saindo do imobilismo que infelizmente predomina dentro desse segmento, não se tornem mais um número a engrossar tão infeliz estatística e que se mobilizem para erradicar esta verdadeira epidemia de ódio".

${ }^{15}$ Um dos primeiros e mais célebres cartazes da campanha de prevenção de HIV/Aids, divulgado pelo GAPA de São Paulo, foi criado pelo artista plástico Darcy Penteado, um dos fundadores do jornal $O$ Lampião.

${ }^{16}$ Uma equipe formada por pessoas oriundas de universidades e de ONGs desenvolveu programas a partir da Subsecretaria de Pesquisa e Cidadania da Secretaria de Segurança Pública do Rio de Janeiro, entre janeiro de 1999 e março de 2000. Entre os programas estavam a criação da Ouvidoria de Polícia, o Programa de Defesa da Mulher e os Centros de Referência das Minorias Sexuais, de Combate à Discriminação Racial e de Defesa Ambiental.

${ }^{17}$ No próprio período de treinamento de voluntários um banco de dados foi estruturado, e os casos comunicados ao DDH através de uma linha telefônica foram monitorados a cada mês.

${ }^{18}$ A partir de 1999, pela divulgação dos dados do DDH, jornais do Rio de Janeiro passaram a cobrir com mais freqüência notícias de violência não-letal contra gays e travestis (LACERDA, 2006, p. 43). 
${ }^{19}$ Sedação da vítima com soníferos e outras substâncias narcóticas, com o objetivo de roubar dinheiro e bens.

${ }^{20}$ Estão envolvidos no projeto o Centro Latino-Americano de Sexualidade e Direitos Humanos (CLAM), do Instituto de Medicina Social da UERJ, e o Centro de Estudos de Segurança e Cidadania (CESeC), da Universidade Mendes. Na medida em que a pesquisa se realiza em diferentes cidades, outros centros vão sendo agregados à parceira, como aconteceu com o Núcleo de Pesquisa sobre o Corpo e da Saúde (NUPACS), da Universidade Federal do Rio Grande do Sul, em Porto Alegre, e o Departamento de Antropologia da Universidade de São Paulo e o PAGU - Núcleo de Estudos de Gênero, da Universidade Estadual de Campinas.

${ }^{21}$ No Rio de Janeiro (2003, 2004), a pesquisa foi realizada com o Grupo Arco-Íris; em Porto Alegre (2004) com o Nuances e, em São Paulo (2005), com a Associação da Parada do Orgulho GLBT de São Paulo.

22 Os pesquisadores de campo, em todas as experiências, são voluntários recrutados nas universidades e no movimento homossexual, treinados por pesquisadores e militantes dos grupos envolvidos.

${ }^{23}$ Brasil Sem Homofobia: Programa de Combate à Violência e à Discriminação contra GLTB e Promoção da Cidadania Homossexual. Brasília: Ministério da Saúde, 2004. Disponível em <www.mj.gov.br/sedh/ct/004_1_3.pdf〉. 
The Problem of Violence against Homosexuals: the Articulation between Activism and Academy in Public Policy Making

Violence against homosexuals is a central theme for activism and for governments and the media as well. This paper aims to analyze the main aspects of the agendas of homosexual movements, that is, of their discourses and practices which influence on public policies to tackle violence. We are particularly interested in identifying the relations between activism and academy within these processes and the way that, based on such relation, a certain type of knowledge is being produced in Brazil.

Key words: Violence; homosexuality; public policies. 